\title{
Characterisation of insulin-resistant phenotype of cultured rat primary adipose cells
}

\author{
C. C. Xiang • Y. J. Wu $\cdot$ L. Ma $\cdot$ L. Ding $\cdot$ I. Lisinski • \\ M. J. Brownstein $\cdot$ S. W. Cushman $\cdot$ X. Chen
}

Received: 5 December 2006 / Accepted: 26 January 2007 / Published online: 23 March 2007

(C) Springer-Verlag 2007

\begin{abstract}
Aims/hypothesis We characterised insulin resistance, metabolic defects and endocrine dysfunction in cultured adipose cells and examined the autocrine or paracrine roles of cytokines/adipokines in the progression of insulin resistance. Materials and methods Rat primary adipose cells were prepared and cultured for 24 and $48 \mathrm{~h}$. Insulin resistance and gene expression were examined by glucose uptake assay, cDNA microarray and real-time RT-PCR.

Results After $24 \mathrm{~h}$ in culture, the fold increase of insulinstimulated glucose uptake in adipose cells was markedly reduced; after $48 \mathrm{~h}$ the response of the cells to insulin decreased. cDNA microarray analysis showed that the
\end{abstract}

Electronic supplementary material The online version of this article (doi:10.1007/s00125-007-0626-z) contains supplementary material, which is available to authorised users.

C. C. Xiang $\cdot$ L. Ma $\cdot$ M. J. Brownstein

Laboratory of Functional Genomics, J. Craig Venter Institute, Rockville, MD, USA

Y. J. Wu

Division of Endocrinology, Diabetes and Bone Disease, Department of Medicine, Mount Sinai School of Medicine, New York, NY, USA

L. Ding $\cdot X$. Chen $(\bowtie)$

Department of Food Science and Nutrition-Room 139,

University of Minnesota,

1334 Eckles Avenue,

St Paul, MN 55108-1038, USA

e-mail: xlchen@umn.edu

I. Lisinski $\cdot$ S. W. Cushman

Experimental Diabetes, Metabolism, and Nutrition Section,

Diabetes Branch, NIDDK/NIH,

Bethesda, MD, USA expression of 514 genes was altered in adipose cells after $24 \mathrm{~h}$ in culture. The dysregulated genes included those involved in the citric acid cycle and in fatty acid and pyruvate metabolism. Specifically, the following genes were all downregulated: genes encoding lipolytic and lipogenic enzymes; uncoupling protein 1 and 2 genes; peroxisome proliferator-activated receptor gamma, coactivator 1 alpha gene. This indicates that lipolytic and lipogenic activity, as well as mitochondria capacity decline in adipose cells cultured for $24 \mathrm{~h}$. The mRNAs encoding 40 adipokines were also dysregulated in cultured cells. Strikingly, the dysregulated adipokines in cultured cells and in freshly isolated adipose cells from insulin-resistant Zucker $f a / f a$ rats displayed a similar pattern with regard to protein functions. Also striking was the fact that progression of insulin resistance was promoted by the adipokines secreted from insulin-resistant adipose tissue or cells. Conclusions/interpretation Our data demonstrate that the impairment of metabolism and endocrine dysfunction in cultured adipose cells mimics the insulin resistance occurring in vivo. Cytokines and adipokines appear to play a critical role in the progression of insulin resistance in adipose cells.

Keywords Adipocyte - Adipokine - Dysregulation . Endocrine · Gene expression - Insulin resistance . Metabolism · Microarray · Mitochondria · Obesity

$\begin{array}{ll}\text { Abbreviations } & \\ \text { ACACB } & \text { acetyl-coenzyme A carboxylase beta; } \\ \text { AKT2 } & \text { thymoma viral proto-oncogene 2 } \\ \text { FASN } & \text { fatty acid synthase } \\ \text { HIF1A } & \text { hypoxia-induced factor 1, alpha subunit; } \\ \text { LIPE } & \text { lipase, hormone sensitive } \\ \text { LPL } & \text { lipoprotein lipase }\end{array}$


PPARA peroxisome proliferator-activated receptor alpha

PPARG peroxisome proliferator-activated receptor gamma

PPARGC1A peroxisome proliferator-activated receptor gamma, coactivator 1 alpha

SLC2A1 and solute carrier family 2 (facilitated glucose

4

SREBF1_V2 sterol regulatory element binding factor 1, variant 2 ;

SCD1 and 2 stearoyl-coenzyme A desaturase 1 and 2 UCP uncoupling protein

\section{Introduction}

Insulin plays a key role in energy metabolism and insulin resistance is at the heart of the metabolic syndrome. Insulin resistance in skeletal muscle, liver and adipose tissue results in hyperglycaemia and, ultimately, diabetes. It is associated with impaired lipid metabolism, decreased fat storage capacity in adipose tissue and ectopic fat accumulation in organs such as liver and muscle [1]. Adipocyte insulin resistance is well defined; it is characterised by decreased solute carrier family 2 (facilitated glucose transporter), member 4 (SLC2A4, previously known as GLUT4) and increased SLC2A, member 1 (SLC2A1, previously known as GLUT1) expression, decreased insulin-stimulated glucose uptake and impaired insulin signal transduction [2]. However, the mechanisms responsible for the development of adipocyte insulin resistance, and the relationship of insulin resistance in adipocytes to full-blown metabolic syndrome are largely unknown.

Adipose tissue is now understood to be a major endocrine organ. Endocrine dysfunction in adipose tissue may play an important role in the pathogenesis of insulin resistance $[3,4]$. Adipose tissue releases a number of factors (so-called adipokines) that have a wide range of functions. Several adipokines such as adiponectin, leptin and resistin are central regulators of insulin sensitivity and whole-body energy metabolism and homeostasis. In addition to releasing adipokines, adipose tissue is also a major source of inflammatory cytokines in obesity. It is clear that adipokines affect insulin sensitivity in endocrine and autocrine or paracrine fashions, i.e. they may have local and systemic actions. Thus, understanding the progressive changes in metabolic and endocrine functions of adipose cells during the development of insulin resistance is vital, if we hope to be effective in preventing insulin resistance and diabetes.

Genetically and diet-induced insulin-resistant and diabetic animals are good models for the pathophysiological study of insulin resistance. However, animal models have limitations for certain types of studies. For example, it is

difficult to investigate the secretory function of adipose cells and evaluate the direct targets of glucose-lowering diabetic drugs or other factors on adipose cells in vivo. For this purpose, an in vitro cell model system that mimics development of insulin resistance in vivo would be valuable. Primary adipose cells have been studied for more than 40 years [5], and have been shown to gradually lose insulin responsiveness in culture [6, 7]. Ruan et al. [7] have shown that insulin resistance in cultured adipose cells is similar to TNF $\alpha$-triggered reprogramming of gene expression, particularly adipogenic gene and inflammatory cytokine expression, but the relevance of these changes to insulin resistance in vivo has not been demonstrated. This demonstration is crucial if primary adipose cells are to be valuable for mechanistic studies of insulin resistance.

The objectives of this study therefore were: (1) to extensively characterise metabolic defects, insulin resistance and endocrine dysfunction of cultured adipose cells by examining global changes in transcription profiles of metabolic genes and of the whole secretory proteome of adipose cells; and (2) to examine the autocrine or paracrine role of adipokines in the progression of insulin resistance. Our data clearly demonstrate that cultured primary adipose cells display impaired lipid metabolism and endocrine dysfunction that are similar to the defects seen in insulin resistance in vivo.

\section{Materials and methods}

Materials Male Sprague-Dawley rats (CD strain; 5-6 weeks old) and male lean and $f a / f a$ Zucker rats were purchased from Charles River Laboratories (Wilmington, MA, USA). Fraction V BSA was from Intergen (Purchase, NY, USA) and type I crude collagenase was from Worthington Biochemical (Freehold, NJ, USA). The rabbit polyclonal anti-SLC2A4 antiserum was raised against a 20-amino acid peptide corresponding to the $\mathrm{COOH}$-terminal sequence of the transporter, kindly supplied by Hoffmann LaRoche (Nutley, NJ, USA). Rabbit antisera for thymoma viral proto-oncogene 2 (AKT2) and $\mathrm{Ser}^{473}$-phosphorylated AKT2 were from Cell Signaling Technology (Beverly, MA, USA). ${ }^{125}$ I-labelled protein A and $\left[\mathrm{U}-{ }^{14} \mathrm{C}\right]$ glucose were from Dupont New England Nuclear (Boston, MA, USA).

Rat primary adipose cell isolation and culture NIH guidelines for animal handling were followed in this study and experimental procedures were approved by the NIDDK Animal Care and Use Committee. For each independent experiment preparation of isolated epididymal adipose cells from eight to ten normal male rats and three Zucker lean and $f a / f a$ rats respectively was performed as described previously [8]. Isolated cells were washed twice with DMEM containing $25 \mathrm{mmol} / 1$ glucose, $25 \mathrm{mmol} / \mathrm{l} \mathrm{HEPES}$, 
$4 \mathrm{mmol} / \mathrm{l} \mathrm{L}$-glutamine, $200 \mathrm{nmol} / \mathrm{l} \mathrm{N6}$-(2-phenylisopropyl)adenosine and $75 \mu \mathrm{g} / \mathrm{ml}$ gentamycin, and subsequently resuspended to a cytocrit of $40 \%\left(5-6 \times 10^{6}\right.$ cells $\left./ \mathrm{ml}\right)$. After a final wash, cells from normal rats were cultured for 24 or $48 \mathrm{~h}$ at $37^{\circ} \mathrm{C}, 5 \% \mathrm{CO}_{2}$ in DMEM containing $3.5 \%$ bovine serum albumin. Then they were collected for mRNA and protein extraction.

$\left[U_{-}{ }^{14} \mathrm{C}\right]$ Glucose uptake assay Glucose transport activity was measured in adipose cells by $\left[\mathrm{U}-{ }^{14} \mathrm{C}\right]$ glucose uptake as described [9]. Adipose cells were incubated with or without insulin for $30 \mathrm{~min}$ before measurement of $\left[\mathrm{U}_{-}{ }^{14} \mathrm{C}\right]$ glucose uptake. Lipid from adipose cells was also extracted using an organic/aqueous phase separation procedure and for the normalisation of samples dried prior to weighing.

Membrane isolation and immunoblotting to detect levels of SLC2A4, AKT2 and $\mathrm{Ser}^{473}$-phosphorylated AKT2 Rat adipose cells were collected after the indicated periods of time in culture. Crude total membrane fractions were prepared essentially as described previously [10]. Proteins in the crude total membranes were separated by SDSpolyacrylamide gel electrophoresis and transferred to nitrocellulose filters. Immunoblot analyses of SLC2A4, AKT2 and $\mathrm{Ser}^{473}$-phosphorylated AKT2 were performed with the anti-SLC2A4, AKT2 and $\mathrm{Ser}^{473}$-phosphorylated AKT2 antibodies and $7.4 \times 10^{3} \mathrm{~Bq}^{125} \mathrm{I}$-labelled protein A. The SLC2A4, AKT2 and $\mathrm{Ser}^{473}$-phosphorylated AKT2 signals were quantified using Image Gauge v3.12, Science Lab 98 (Fuji Photo Film, Tokyo, Japan).

cDNA microarray: microarray fabrication Mouse cDNA microarrays with a total of 10,816 elements were printed on poly-L-lysine-coated slides. Mouse cDNA microarrays can be used for rat studies, as indicated in a previous study [11]. The cDNAs used were provided by B. Soares (Departments of Pediatrics and Physiology and Biophysics, University of Iowa). Plasmids were extracted from the bacteria using QiaPrep Turbo kits and a BioRobot 8000 (Qiagen, Valencia, CA, USA). The cDNA inserts were amplified with modified M13 primers (M13F 5'-GTTGTAAAAC GACGGCCAGTG-3' and M13R 5'-CACACAGGAAA CAGCTATG-3') and purified with MultiScreen PCR plates (Millipore, Billerica, MA, USA). Detailed descriptions of coating glass with poly-L-lysine and post-processing of the printed slides are available at: http://cmgm.stanford.edu/ pbrown/mguide/index.html.

RNA extraction and labelling Total RNA from isolated adipose cells was extracted using a reagent (TRIzol; Invitrogen, Carlsbad, CA, USA) according to the manufacturer's instructions. In this study, three independent experiments per time point and three cDNA microarrays per RNA sample were used. For each experiment, total RNA of cultured cells from six to eight rats or three Zucker lean and $f a / f a$ rats respectively was pooled and subjected to subsequent cDNA synthesis, labelling, hybridisation and analysis. First- and second-strand cDNA syntheses, labelling, hybridisation and washing were performed as described [12].

Array scanning and data analysis The arrays were scanned with a scanner (GenePix 4000A; Molecular Devices, Sunnyvale, CA, USA) at $10 \mu \mathrm{m}$ resolution. The photomultiplier tube voltage settings were varied to obtain the maximum signal intensities with $<1 \%$ probe saturation. The resulting images were analysed using IPLab (Scanalytics, Rockville, MD, USA) and ArraySuite (NHGRI, Bethesda, MD, USA) software. In all the experiments described, ratios were assigned quality scores $[12,13]$ and those with scores of $<1$ were removed from the data sets. Class comparison between red and green channels was performed using univariate paired $t$ test (with random variance model) to identify the differentially expressed genes that were statistically significant at $p<0.05$ (mAdb Gateway and BRB Array Tools; http://madb.nci.nih.gov). The differentially expressed genes were subjected to pathways analysis using web-based software (https://analysis.ingenuity.com).

Quantitative real-time RT-PCR Total RNA extraction was carried out as described above. RNA was then treated with RQ1 DNase (Promega, Madison, WI, USA) at $37^{\circ} \mathrm{C}$ for $30 \mathrm{~min}$, followed by extraction with phenol-chloroform and ethanol precipitation. The first-strand cDNA was generated using the oligo (dT) primer in the 1st-Strand cDNA Synthesis Kit (Promega). cDNA samples were then diluted 1:20 and $10 \mu l$ of diluted cDNA was used in each $25-\mu 1$ real-time PCR reaction, using the SYBR GreenER qPCR SuperMix Universal (Invitrogen) with an ABI 7500 Real Time PCR System (Applied Biosystems, Foster City, CA, USA) and the Absolute Quantation method. Primers specific for nine genes are listed in Electronic supplementary material (ESM) Table 1. Results of quantitivate PCR assays were analysed using the software supplied with the ABI 7500 system. A standard curve for each primer set was generated in each assay and used to derive the copy number of target sequences in unknown samples. $\beta$-Actin was selected as an internal standard. All raw data are expressed as the ratio of the selected gene to $\beta$-actin. Statistical significance was determined by two-tailed Student's $t$ test.

\section{Results}

Primary adipose cells in culture progressively lose insulin responsiveness of glucose uptake and Slc2a4 expression over time Changes in glucose metabolism of adipose cells 
Table 1 Expression of genes involved in metabolic pathways in cells cultured for $24 \mathrm{~h}$ and $48 \mathrm{~h}$

\begin{tabular}{|c|c|c|c|}
\hline Accession & Gene & $\begin{array}{l}\text { Geometric mean of ratios } \\
\text { Values at } 24 \mathrm{~h}: 0 \mathrm{~h}\end{array}$ & $\begin{array}{l}\text { Geometric mean of ratios } \\
\text { Values at } 48 \mathrm{~h}: 0 \mathrm{~h}\end{array}$ \\
\hline \multicolumn{4}{|l|}{ Citrate cycle } \\
\hline NM_134037 & ATP citrate lyase & -2.89 & -2.34 \\
\hline NM_026444 & Citrate synthase & -1.61 & No change \\
\hline NM_173011 & Isocitrate dehydrogenase 2 & -2.9 & -2.53 \\
\hline NM_008617 & Malate dehydrogenase 2 & -2.06 & -2.38 \\
\hline NM_010956 & Oxoglutarate dehydrogenase & -1.74 & No change \\
\hline NM_008797 & Pyruvate decarboxylase & -2.07 & -1.54 \\
\hline \multicolumn{4}{|c|}{ Fatty acid biosynthesis and metabolism } \\
\hline NM_007988 & Fatty acid synthase & -12.25 & -3.4 \\
\hline $\mathrm{BC} 0 \overline{6}_{4712}$ & L-3-Hydroxyacyl-coenzyme A dehydrogenase, short chain & -4.57 & -2.5 \\
\hline NM_008292 & Hydroxysteroid (17-beta) dehydrogenase 4 & -1.56 & No change \\
\hline NM_011327 & Acyl-coenzyme A dehydrogenase (4 to 12 straight chain) & -2.55 & No change \\
\hline NM_017366 & Acyl-coenzyme A dehydrogenase (very long chain) & 2.29 & No change \\
\hline \multicolumn{4}{|c|}{ Oxidative phosphorylation } \\
\hline NM_026536 & ATP synthase & -2.06 & No change \\
\hline NM_009944 & Cytochrome $\mathrm{C}$ oxidase & 1.37 & No change \\
\hline \multicolumn{4}{|c|}{ Pyruvate metabolism } \\
\hline NM_030611 & Aldo-keto reductase family 1 & 7.09 & No change \\
\hline AY 217337 & Malic enzyme & -4.3 & -2.45 \\
\hline XM_918156 & Pyruvate dehydrogenase-beta & -5.67 & -2.4 \\
\hline D63764 & Pyruvate kinase & 1.57 & 2.82 \\
\hline
\end{tabular}

were investigated by measuring insulin-stimulated glucose uptake and SLC2A4 synthesis in adipose cells cultured for 24 and 48 h. As illustrated in Fig. 1a, fresh cells showed about a ninefold increase of glucose uptake in response to insulin, this response being reduced to about twofold after $24 \mathrm{~h}$ ( $p=0.007, t$ test), mainly due to an increase in basal levels of glucose uptake. It was also reduced to about twofold after $48 \mathrm{~h}$ culture ( $p=0.006, t$ test). The absolute levels of glucose uptake in the insulin-stimulated state displayed a marginal decrease in cells cultured for $24 \mathrm{~h}$ ( $p=0.07, t$ test) and a further reduction after $48 \mathrm{~h}$ of culture ( $p=0.02, t$ test) compared with freshly isolated adipose cells. Moreover, mRNA expression of Slc2a4 and SLC2A4 protein synthesis declined in a time-dependent manner (Fig. 1b). Thus, glucometabolic insulin sensitivity in culture deteriorated over time.

Changes in the expression profile of cultured adipose cells To determine whether there are differences in gene expression between adipose cells with different degrees of insulin resistance, we examined transcriptional profiles in adipose cells treated as described above. cDNA microarrays were hybridised with labelled targets and all sample RNAs were compared with RNA from freshly isolated adipose cells. The genes that changed significantly were further analysed for their cellular functions and their metabolic and signalling pathways. Compared with freshly isolated adipose cells, cells cultured for $24 \mathrm{~h}$ showed 514 differentially expressed genes, 220 upregulated and 296 downregulated.
We performed pathways analyses of the genes that showed statistically significant differences in cultured cells. Interestingly, genes involved in many metabolic pathways, in particular the citrate cycle, and fatty acid and pyruvate metabolism, were among those that changed after $24 \mathrm{~h}$ of culture. As noted, most of them showed decreased expression (Table 1). Furthermore, the expression levels of respiratory uncoupling protein $(U c p) 2$ and $U c p 3$ genes, which increase the proton leak in mitochondria, decreased in adipose cells at $24 \mathrm{~h}$, as did expression of peroxisome proliferator-activated receptor gamma (Pparg), coactivator 1 alpha (Ppargcla; previously known as Pgcl $\alpha$ ), an activator of mitochondrial biogenesis (Fig. 2). Hypoxia-induced factor 1, alpha sub-unit (HIF1A) is a key transcription factor that regulates adaptive response to hypoxia; expression of Hifla is inversely related to mitochondrial function [14]. Hifla expression was significantly increased by $\sim 2.5-$ and $\sim 1.8$ fold in cells after 24 and $48 \mathrm{~h}$ culture, respectively (Fig. 2). These data suggest that mitochondrial activity and energy production are reduced in insulin-resistant adipose cells after $24 \mathrm{~h}$ of culture.

Culturing primary adipose cells in vitro affects lipid metabolism As lipid metabolism is the predominant function of adipose tissue, it is of great interest to know how lipid metabolism is altered in adipose cells and how these changes are linked to the degree of glucometabolic insulin resistance. As shown in Fig. 3, lipogenic genes such as fatty acid synthase (Fasn), fatty acid desaturase 1, malic enzyme, 


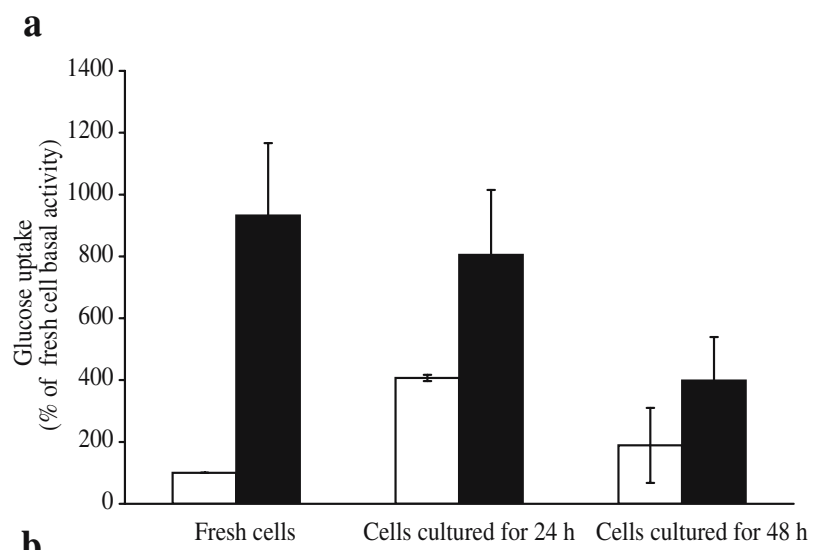

b

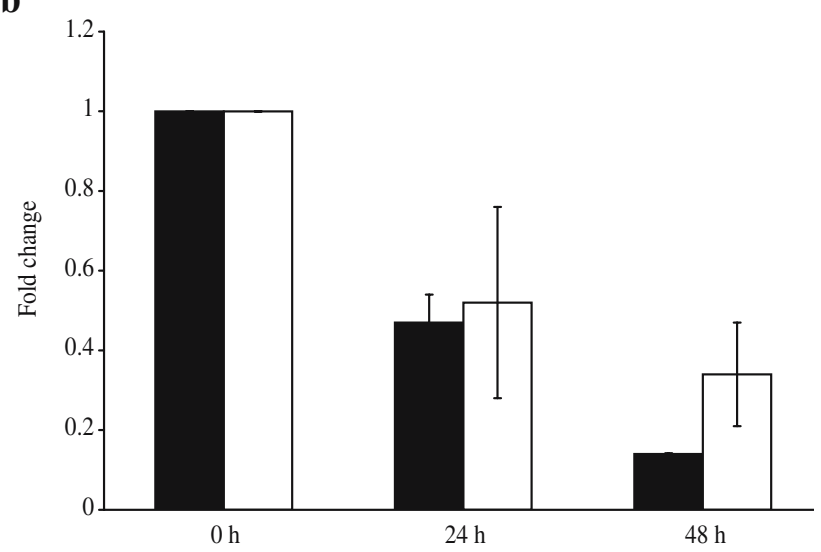

Fig. 1 Dysregulation of glucose transport activity (a) and SCL2A4 protein and mRNA expression (b) in adipose cells after 24 and $48 \mathrm{~h}$ in culture. a Freshly isolated adipose cells and adipose cells after 24 and $48 \mathrm{~h}$ in culture were treated with (black bars) or without (white bars) insulin for $30 \mathrm{~min}$. The cells were then pulsed with $\left[\mathrm{U}_{-}{ }^{14} \mathrm{C}\right]$ glucose. Radioactivity was expressed relative to the basal value of fresh cells in each experiment. Glucose uptake was calculated as described in Materials and methods. Results are means \pm SEM of the means obtained from triplicate determinations in each of three independent experiments. b After collection of cells, total cell membrane proteins were prepared from the fresh or cultured cells by differential centrifugation. $20 \mu \mathrm{g}$ of protein were subjected to immunoblotting with anti-SLC2A4 antibody. The signals of SLC2A4 proteins were quantified from three independent experiments. Total RNA was extracted from the cells with the above culture conditions. Quantitative real-time PCR was performed to detect mRNA expression. The protein (white bar) or mRNA (black bar) levels in each condition were normalised to the level in control $(0 \mathrm{~h})$ and are shown as fold changes. Error bars: SEM

glycerol-3-phosphate acyltransferase, ATP citrate lyase and stearoyl-coenzyme A desaturase $1(S c d 1)$ and $2(S c d 2)$ were markedly reduced in adipose cells following 24 and $48 \mathrm{~h}$ of culture. The expression levels of genes encoding fatty acid transporters 3 and 4 and fatty acid binding protein 4 , which mediate fatty acid transport, were also all decreased, as were genes encoding enzymes important for triacyclglycerol hydrolysis in adipose tissue, e.g. lipase, hormone sensitive (Lipe, previously known as $H s l$ ), monoglyceride lipase and adiponutrin after 24 and $48 \mathrm{~h}$ in vitro.

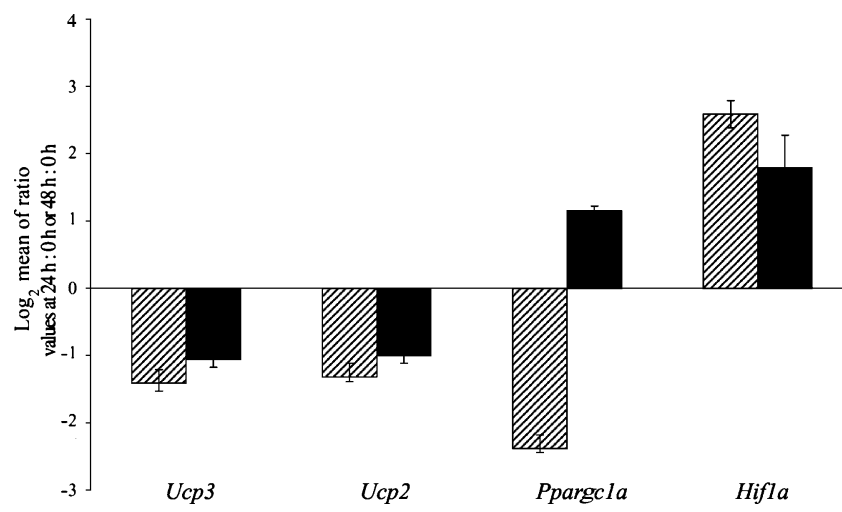

Fig. 2 Expression of Ucp2, Ucp3, Ppargcla and Hifla in adipose cells after $24 \mathrm{~h}$ (hatched bars) and $48 \mathrm{~h}$ (black bars) in culture. Results are expressed as geometric means of the ratio of values at $24 \mathrm{~h}: 0 \mathrm{~h}$ or values at $48 \mathrm{~h}: 0 \mathrm{~h}$. Values are means \pm SEM from cDNA microarrays. All four genes were found to be differentially expressed by univariate paired $t$ test at $p<0.05$ level as described in Materials and methods

Importantly, lipolytic activity in the cultured cells was also inhibited. Expression of the $\beta_{2}$-adrenoreceptor, which stimulates lipolysis in adipose tissue, decreased at 24 and $48 \mathrm{~h}$, while that of the $\alpha 1$-adrenoreceptor, which has an anti-lipolytic effect, was unchanged at $24 \mathrm{~h}$, but increased at $48 \mathrm{~h}$ (Fig. 3).

Culturing primary adipose cells results in endocrine dysfunction It is useful to know why cultured adipose cells change their gene expression and metabolic characteristics while losing insulin sensitivity during culture, as such phenomena may have implications for in vitro study of the mechanisms leading to development of insulin resistance. We speculated that alterations in adipokine production may play a role in this process, as many inflammatory cytokines have been known to modulate adipocyte metabolism. We have previously shown that adipose cells secrete a large number of adipokines with multiple functions into the

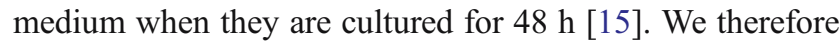
examined the expression levels of the genes encoding these adipokines. As shown in ESM Table 2, 40 secretory protein transcripts were changed by more than 1.5 -fold in adipose cells after 24 and $48 \mathrm{~h}$ in culture. The patterns of up- or downregulation of transcripts were similar at both time points.

To examine whether secretory dysfunction of adipose cells occurs in insulin resistance in vivo and what, if any, similarities are shared with those seen in cultured cells, we compared gene expression of the proteins that were dysregulated in cultured cells with that of the same proteins in adipose cells from Zucker fa/fa rats. Among 40 secreted proteins with altered expression in cultured cells, 30 demonstrated dysregulated expression in adipose cells from Zucker $f a / f a$ rats when compared with lean rats. Notably, 21 of these 30 secreted proteins displayed the same patterns of 
Fig. 3 Expression of genes encoding lipogenic and lipolytic enzymes in adipose cells after $24 \mathrm{~h}$ (hatched bars) and $48 \mathrm{~h}$ (black bars) in culture. Results are expressed as geometric mean of ratios (value at $24 \mathrm{~h}: 0 \mathrm{~h}$ or value at $48 \mathrm{~h}: 0 \mathrm{~h}$ ). Values are means \pm SEM from cDNA microarrays. All genes were found to be differentially expressed by univariate paired $t$ test at $p<0.05$ level as described in Materials and methods

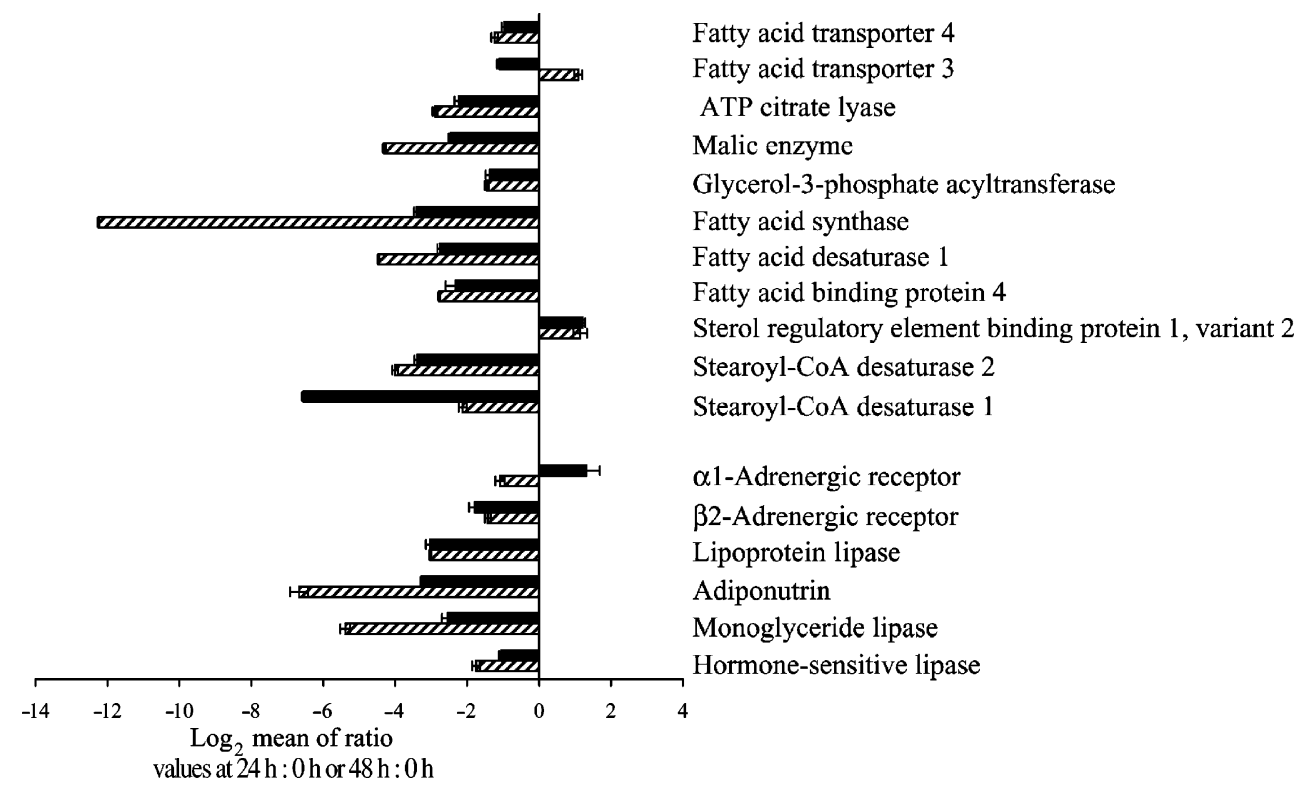

up- and downregulation of transcripts as that seen in the adipose cells after 24 and $48 \mathrm{~h}$ in culture (ESM Table 3). Gene ontology analysis (http://www.geneontology.org) showed that the dysregulated proteins are involved in the following major molecular functions or biological processes: inflammatory responses, blood pressure regulation, blood coagulation, angiogenesis, apoptosis, glucose metabolism, extracellular matrix organisation and biogenesis, proteolysis and cell proliferation/differentiation (ESM Table 3).

Autocrine and paracrine regulation of progression of insulin resistance in vitro is affected by adipokines We observed decreased insulin-stimulated glucose uptake in fresh adipose cells cultured in adipose cell-conditioned medium (data not shown). This suggests that the deterioration of insulin sensitivity in adipose cells after $48 \mathrm{~h}$ in culture could be associated with the detrimental effects of adipokines secreted into the culture medium over time. To test the above possibility, fresh adipose cells were cocultured with or without intact adipose tissue from the same normal rats for $24 \mathrm{~h}$ to examine whether the imbalanced production of cytokines/adipokines from adipose tissue and isolated adipose cells accelerated the progression of insulin resistance. After $24 \mathrm{~h}$ in culture, isolated adipose cells and intact tissue were separated again using $240 \mu \mathrm{mol} / 1 \mathrm{mesh}$, and SLC2A4 protein production and AKT phosphorylation in response to insulin were examined in isolated adipose cells. Strikingly, $24 \mathrm{~h}$ co-culturing with intact adipose tissue reduced insulin responsiveness to SLC2A4 protein production and AKT phosphorylation to a greater extent than in adipose cells that had not been co-cultured with adipose tissue (Fig. 4). Moreover, the conditioned medium from adipose cells cultured for $48 \mathrm{~h}$ was able to mimic the negative effect of co-culturing on insulin resistance (data not shown). These data suggest that the time effect on the progression of glucometabolic insulin resistance is mediated by adipokines.

Real-time PCR confirmation of microarray gene expression To validate the results of microarray-based gene expression analysis, we examined expression of the key genes involved in metabolic pathways and insulin sensitivity by quantitative real-time RT-PCR. The selected genes include those encoding key enzymes involved in lipogenic and lipolytic activities (Fasn, acetyl-coenzyme A carboxylase beta $[A c a c b]$, lipoprotein lipase $[L p l]$, Lipe and Ppargcla) (Fig. 5a), as well as genes serving as insulin-resistance markers (Fig. 5b). The quantitative real-time RT-PCR results of all nine genes examined were completely concordant with microarray-based gene expression data. Notably, expression of lipogenic and lipolytic genes significantly decreased after $24 \mathrm{~h}$ culture (Fasn, $p=0.013$; Lpl, $p=0.001 ;$ Lipe, $p=0.032 ;$ Acacb, $p=0.023 ; t$ test, 24 vs $0 \mathrm{~h}$ ) with no further reductions after $48 \mathrm{~h}$ culture (Fig. 5a). In contrast, expression of insulin-resistance markers (Slc2a4, Pparg, leptin and adiponectin) showed only a moderate reduction after $24 \mathrm{~h}$ culture (Slc2a4: $p=0.046$; Pparg: $p=0.089$; leptin: $p=0.256$; adiponectin: $p=0.026$; $t$ test, 24 vs $0 \mathrm{~h}$ ), but a further marked decrease after $48 \mathrm{~h}$ culture (Slc2a4: $p=0.011$; Pparg: $p=0.023$; leptin: $p=0.011$; adiponectin: $p=0.022 ; t$ test, 48 vs 0 h) (Fig. 5b). More interestingly, $24 \mathrm{~h}$ co-culturing with adipose tissue resulted in a significant reduction in the gene expression of insulinresistance markers to an extent similar to that seen in cells cultured for $48 \mathrm{~h}$ (Slc2a4: $p=0.008$; Pparg: $p=0.013$; leptin: $p=0.015$; adiponectin: $p=0.054 ; t$ test, $24 \mathrm{~h}+$ adipose tissue vs 0 h) (Fig. 5b). 
a Culture time (h) $\begin{array}{llllll}0 & 24 & 24 & 24 & 24\end{array}$

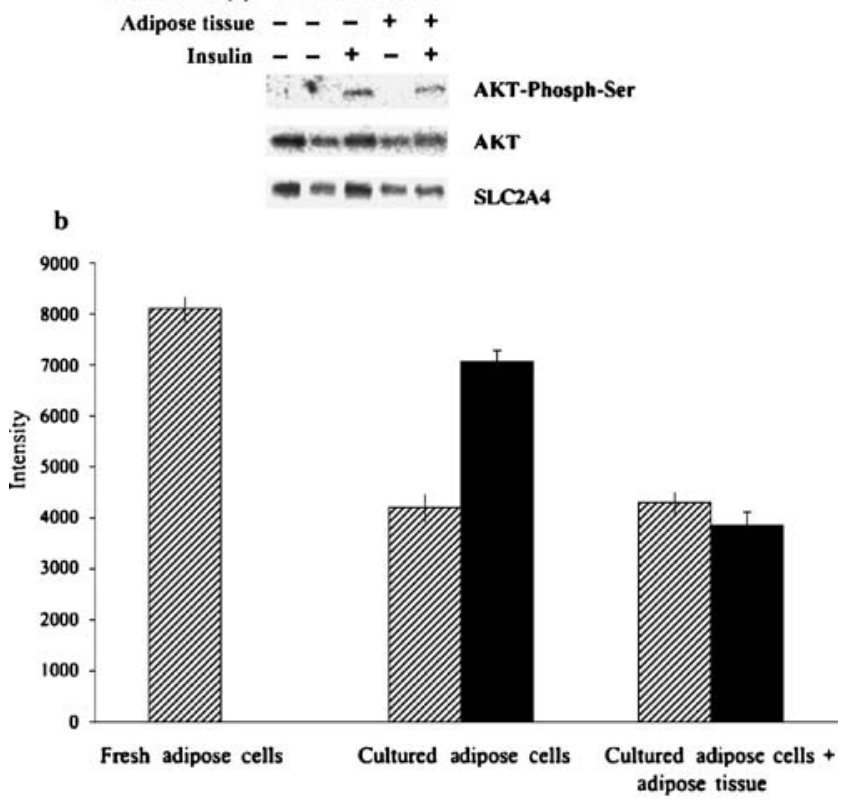

Fig. 4 Total SLC2A4 production and phosphorylation of AKT2 at Ser474 in adipose cells (a) after $24 \mathrm{~h}$ co-culturing with intact adipose tissue from normal rats. The same amount of isolated adipose cells was cultured alone or co-cultured with intact adipose tissue for $24 \mathrm{~h}$. After incubation, the cells were collected and total cell membrane proteins were prepared from cells in the basal and insulin-stimulated $(67 \mathrm{nmol} / \mathrm{l})$ states by differential centrifugation. a $20 \mu \mathrm{g}$ of protein were subjected to immunoblotting with anti-SLC2A4, AKT2 and $\mathrm{Ser}^{473}$-phosphorylated AKT2 antibody. b The signals of SLC2A4 proteins were quantified and presented as intensity from three independent experiments. Hatched bars, basal; black bars, insulin-stimulated as above

\section{Discussion}

In this study, we characterised metabolism, secretion and gene expression patterns of primary adipose cells as they developed insulin resistance. Our data show that the cells reduce their production of energy and mitochondrial capacity, as indicated by downregulation of genes involved in the citric acid cycle, fatty acid metabolism, and pyruvate metabolism, as well as those involved in respiratory uncoupling proteins and activation of mitochondria biosynthesis. Furthermore, lipolytic and lipogenic activities were inhibited as cultured adipose cells developed insulin resistance. These changes resemble those seen when insulin resistance develops in vivo in connection with obesity and type 2 diabetes. Interestingly, the defects in lipid metabolism appear earlier than the complete loss of insulin responsiveness to glucose uptake and metabolism. The expression of genes encoding 40 secretory proteins was seen to change as adipose cells developed insulin resistance. Moreover, factors secreted by the cultured cells appeared to accelerate the development of insulin resistance.

Lipogenesis, fat oxidation and lipolysis are important factors controlling energy balance. In obese humans, the
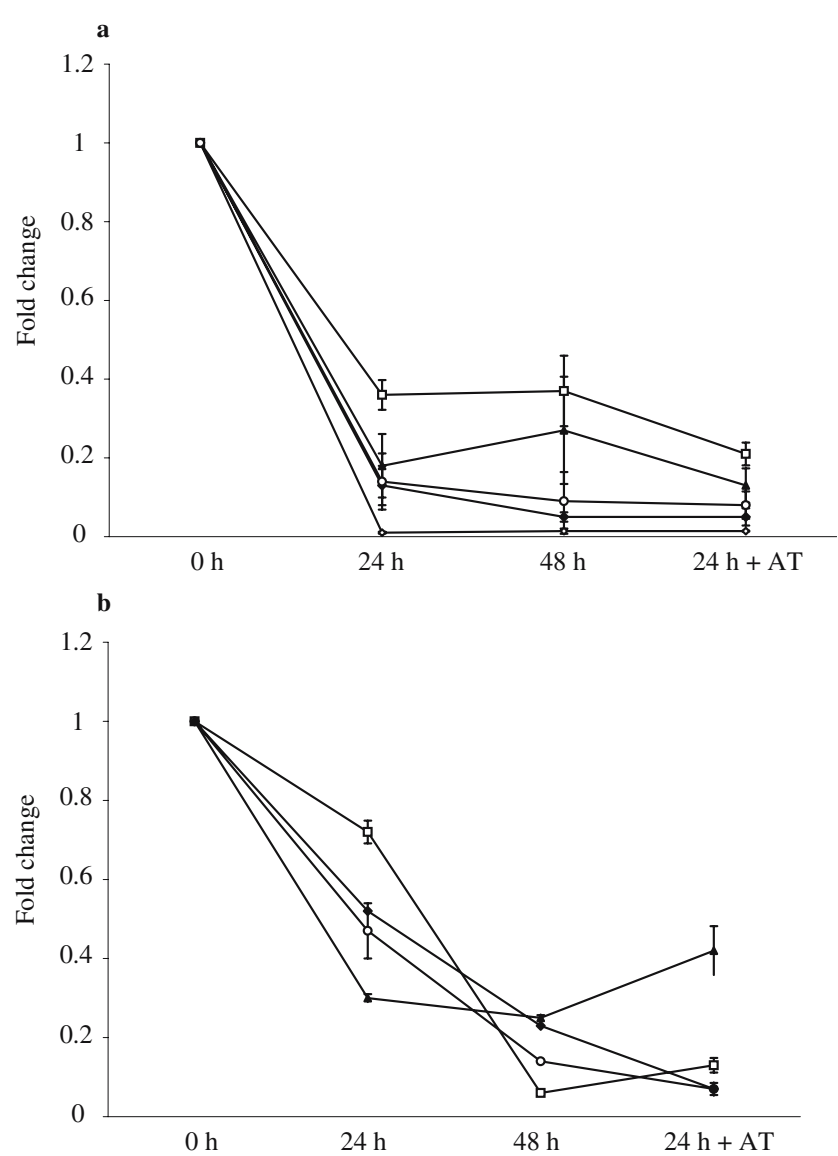

Fig. 5 Validation of microarray results by quantitative real-time PCR. An independent analysis was performed to confirm the expression of nine selected key genes that were altered in different culturing conditions according to microarrays. a Selected genes encoding enzymes involved in lipid metabolism: Fasn (open diamond), Acacb (closed diamond), Lpl (open square), Lipe (closed triangle), and Ppargcla (open circle). b Genes for insulin-resistance markers: Slc2a4 (open circle), leptin (open square), adiponectin (closed triangle), and Ppaarg (closed diamond). The expression levels in each condition were normalised to the level in control $(0 \mathrm{~h})$ and are shown as fold changes. Error bars: SEM

lipolytic capacity of adipose cells is decreased [16-18], a decrease associated with reduced expression of LIPE and lipolytic $\beta_{2}$-adrenoreceptor [19], and increased expression of $\alpha_{2}$-adrenoreceptor [20]. In addition, fat oxidation declines, as determined by reduced ATP production [21] and mitochondrial capacity $[22,23]$ in obesity and diabetes. In our cultured adipose cells, downregulation of Lipe, monoglyceride lipase 2 , adiponutrin and $\beta_{2}$-adrenoreceptor is indicative of decreased lipolytic activity. In addition, six genes in the citrate cycle, as well as Ucp2 and -3 and Ppargcla, were all downregulated in adipose cells cultured for $24 \mathrm{~h}$. Our result is consistent with the observation that expression of genes involved in mitochondrial biosynthesis, such as PPARGC1A, UCP1, carnitine palmitoyltransferase 1 and PPAR alpha (PPARA) were decreased in subcutaneous adipose tissue of type 2 diabetic patients [24]. Other studies 
have reported that fat tissue is hypoxic in obesity [25-27]. Expression of $H I F 1 A$, a key transcription factor which regulates the adaptive response to hypoxia, is upregulated in adipose tissue of human obese subjects and decreased after weight loss [27]. Interestingly, in the present study, we also perceived increased Hifla expression in cultured adipose cells under ambient oxygen tension, indicating that this increase appears to be independent of hypoxia. Taking these results together, cultured adipose cells seem similar to cells from obese and insulin-resistant subjects.

In obesity, altered lipogenesis is seen in insulin-responsive tissues such as liver, skeletal muscle and adipose tissue along with changes in lipolysis. Sterol regulatory element binding factor 1, variant 2 (Srebf1_v2), a lipogenic transcription factor, regulates the expression of many of the genes involved in fatty acid and triacylglycerol synthesis [5]. This key lipogenic regulator has been observed to be downregulated in adipose tissue of morbidly obese humans [28] and in first-degree relatives of patients with insulin resistance [29], indicating that lipogenesis declines in adipose tissue in obesity and insulin resistance. In contrast, expression of Srebf1_v2 in non-adipose tissues of obese animals is elevated, this increase being associated with increased lipogenic activities and ectopic fat storage in liver and muscle in insulin resistance [30,31]. Consistent with in vivo observations, our results show that lipogenesis decreases in cultured adipose cells. In these cells, therefore, the following genes were dramatically downregulated: $F a s n, S c d 1, S c d 2$ and genes encoding fatty acid desaturase, malic enzyme, glycerol-3-phosphate acyltransferase and ATP citrate lyase.

The endocrine function of adipose tissue and its role in the development of insulin resistance has been recognised, but the nature of the factors that are secreted by adipose tissue and contribute to obesity and metabolic syndrome is not completely understood. In this study, we found that mRNA expression of 30 secretory proteins was changed in insulinresistant adipose cells of both experimental models and Zucker $f a / f a$ rats. This set of secreted proteins, which are often changed in insulin resistance, may be potential molecular mediators linking obesity to type 2 diabetes. Moreover, functional grouping analysis demonstrates that similar categories of secreted proteins, such as inflammatory cytokines, immune-related factors, extracellular matrix proteins and factors involved in vasculature, collagens, proteases and others, were dysregulated in two different insulin-resistance models. This suggests that endocrine dysfunction is the common feature developed in insulin-resistant adipose cells in vitro and in vivo. Our data strongly support the concept that adipose-cell-secreted proteins serve as mediators for the pathogenesis of insulin resistance and metabolic syndrome.

Adipose tissue inflammation has been associated with obesity and insulin resistance. Macrophage-produced inflam- matory cytokines and adipocyte-derived factors (adipokines) regulate insulin sensitivity and metabolism through a mechanism involving cross-talk between macrophages and adipose cells. Inflammatory cytokines locally modulate adipocyte differentiation $[32,33]$ and secretion of signalling molecules $[34,35]$ that subsequently regulate systemic insulin sensitivity. On the other hand, adipokines could modulate the functions of macrophages and production of inflammatory cytokines [36]. Our data demonstrate that co-culturing with intact adipose tissue for $24 \mathrm{~h}$ led to a further reduction in the response of the cells to insulin and in the expression of insulin-resistance markers (Slc2a4, leptin and Pparg). This indicates that insulin resistance in cells cultured for $24 \mathrm{~h}$ is worsened by the presence of intact adipose tissue. Thus, it is possible that inflammatory cytokines and adipokines might participate in a negative feedback loop between macrophages present in adipose tissue and adipose cells, contributing to the detrimental effect of co-cultured adipose tissue on isolated adipose cells.

Adipose cell functions are regulated by a number of neural, nutritional and endocrine circadian signals. Circadian rhythms of gene expression have been observed in adipose tissue [37,38], and the alteration of this gene expression rhythm has been associated with obesity [39, 40]. Endocrine signals are also important for normal functions of adipose secretion. For instance, studies by Russell et al. demonstrated that insulin and dexamethasone are required by cultured human adipocytes to maintain basal levels of leptin secretion [41]. Isolating and culturing adipose cells obviously result in the loss of those signals/ regulators. This may trigger the changes we have seen, supporting the observations made in vivo that a complex of endocrine changes is involved in the development of obesity and insulin resistance, as well as the notion that cytokines/adipokines, acting as local factors, contribute to the development of insulin resistance in adipose cells.

In summary, our data provide evidence that cultured adipose cells develop insulin resistance, impaired lipid metabolism and adipokine production. These characteristics are similar to insulin resistance in vivo, suggesting that cultured primary adipose cells may be a good model of insulin resistance in vitro. Our data also suggest that a functional imbalance of many, rather than of few, adipokines may mediate the progression of insulin resistance and metabolic changes in the cultured cells. To understand the process completely, it will be essential to investigate individual adipokines, some of which may drive insulin resistance, and others of which may alter cellular metabolism through different mechanisms involving multiple signalling pathways. Our studies provide an extensive list of adipokines that are dysregulated in insulin resistance and potentially of great pathological significance in obesitylinked metabolic syndrome. 
Duality of interest The authors have no dualities of interest.

\section{References}

1. Heilbronn L, Smith SR, Ravussin E (2004) Failure of fat cell proliferation, mitochondrial function and fat oxidation results in ectopic fat storage, insulin resistance and type II diabetes mellitus. Int J Obes Relat Metab Disord 28(Suppl 4):S12S21

2. Kahn BB, Flier JS (2000) Obesity and insulin resistance. J Clin Invest 106:473-481

3. Bergman RN, Van Citters GW, Mittelman SD et al (2001) Central role of the adipocyte in the metabolic syndrome. J Investig Med 49:119-126

4. Hotamisligil GS (2000) Molecular mechanisms of insulin resistance and the role of the adipocyte. Int J Obes Relat Metab Disord 24(Suppl 4):S23-S27

5. Shimano H, Shimomura I, Hammer RE et al (1997) Elevated levels of SREBP-2 and cholesterol synthesis in livers of mice homozygous for a targeted disruption of the SREBP-1 gene. J Clin Invest 100:2115-2124

6. Gerrits PM, Olson AL, Pessin JE (1993) Regulation of the GLUT4/muscle-fat glucose transporter mRNA in adipose tissue of insulin-deficient diabetic rats. J Biol Chem 268:640-644

7. Ruan H, Zarnowski MJ, Cushman SW, Lodish HF (2003) Standard isolation of primary adipose cells from mouse epididymal fat pads induces inflammatory mediators and down-regulates adipocyte genes. J Biol Chem 278:47585-47593

8. Weber TM, Joost HG, Simpson IA, Cushman SW (1988) The insulin receptor. Liss, New York, pp 171-187

9. Gliemann J, Rees WD, Foley JA (1984) The fate of labelled glucose molecules in the rat adipocyte. Dependence on glucose concentration. Biochim Biophys Acta 804:68-76

10. Chen H, Wertheimer SJ, Lin CH et al (1997) Protein-tyrosine phosphatases PTP1B and syp are modulators of insulin-stimulated translocation of GLUT4 in transfected rat adipose cells. J Biol Chem 272:8026-8031

11. Mutsuga N, Shahar T, Verbalis JG et al (2004) Selective gene expression in magnocellular neurons in rat supraoptic nucleus. J Neurosci 24:7174-7185

12. Xiang CC, Kozhich OA, Chen M et al (2002) Amine-modified random primers to label probes for DNA microarrays. Nat Biotechnol 20:738-742

13. Chen Y, Kamat V, Dougherty ER, Bittner ML, Meltzer PS, Trent JM (2002) Ratio statistics of gene expression levels and applications to microarray data analysis. Bioinformatics 18:1207-1215

14. Piruat JI, Lopez-Barneo J (2005) Oxygen tension regulates mitochondrial DNA-encoded complex I gene expression. J Biol Chem 280:42676-42684

15. Chen X, Cushman SW, Pannell LK, Hess S (2005) Quantitative proteomic analysis of the secretory proteins from rat adipose cells using a 2D liquid chromatography-MS/MS approach. J Proteome Res 4:570-577

16. Jensen MD, Haymond MW, Rizza RA, Cryer PE, Miles JM (1989) Influence of body fat distribution on free fatty acid metabolism in obesity. J Clin Invest 83:1168-1173

17. Bougneres P, Stunff CL, Pecqueur C, Pinglier E, Adnot P, Ricquier D (1997) In vivo resistance of lipolysis to epinephrine. A new feature of childhood onset obesity. J Clin Invest 99: $2568-2573$

18. Langin D, Dicker A, Tavernier G et al (2005) Adipocyte lipases and defect of lipolysis in human obesity. Diabetes 54:31903197
19. Reynisdottir S, Wahrenberg H, Carlstrom K, Rossner S, Arner $P$ (1994) Catecholamine resistance in fat cells of women with upperbody obesity due to decreased expression of beta 2-adrenoceptors. Diabetologia 37:428-435

20. Mauriege P, Despres JP, Prud'homme D et al (1991) Regional variation in adipose tissue lipolysis in lean and obese men. J Lipid Res 32:1625-1633

21. Kelley DE, He J, Menshikova EV, Ritov VB (2002) Dysfunction of mitochondria in human skeletal muscle in type 2 diabetes. Diabetes 51:2944-2950

22. Patti ME, Butte AJ, Crunkhorn S et al (2003) Coordinated reduction of genes of oxidative metabolism in humans with insulin resistance and diabetes: potential role of PGC1 and NRF1. Proc Natl Acad Sci U S A 100:8466-8471

23. Mootha VK, Lindgren CM, Eriksson KF et al (2003) PGC1alpha-responsive genes involved in oxidative phosphorylation are coordinately downregulated in human diabetes. Nat Genet 34:267-273

24. Bogacka I, Xie H, Bray GA, Smith SR (2005) Pioglitazone induces mitochondrial biogenesis in human subcutaneous adipose tissue in vivo. Diabetes 54:1392-1399

25. Fleischmann E, Kurz A, Niedermayr M et al (2005) Tissue oxygenation in obese and non-obese patients during laparoscopy. Obes Surg 15:813-819

26. Kabon B, Nagele A, Reddy D et al (2004) Obesity decreases perioperative tissue oxygenation. Anesthesiology 100:274-280

27. Cancello R, Henegar C, Viguerie N et al (2005) Reduction of macrophage infiltration and chemoattractant gene expression changes in white adipose tissue of morbidly obese subjects after surgery-induced weight loss. Diabetes 54:2277-2286

28. Sewter C, Berger D, Considine RV et al (2002) Human obesity and type 2 diabetes are associated with alterations in SREBP1 isoform expression that are reproduced ex vivo by tumor necrosis factor-alpha. Diabetes 51:1035-1041

29. Yang X, Jansson PA, Nagaev I et al (2004) Evidence of impaired adipogenesis in insulin resistance. Biochem Biophys Res Commun 317:1045-1051

30. Shimomura I, Bashmakov Y, Horton JD (1999) Increased levels of nuclear SREBP-1c associated with fatty livers in two mouse models of diabetes mellitus. J Biol Chem 274:30028-30032

31. Kakuma T, Lee Y, Higa M et al (2000) Leptin, troglitazone, and the expression of sterol regulatory element binding proteins in liver and pancreatic islets. Proc Natl Acad Sci U S A 97:85368541

32. Xu H, Sethi JK, Hotamisligil GS (1999) Transmembrane tumor necrosis factor (TNF)-alpha inhibits adipocyte differentiation by selectively activating TNF receptor 1 . J Biol Chem 274:2628726295

33. Gregoire FM, Smas CM, Sul HS (1998) Understanding adipocyte differentiation. Physiol Rev 78:783-809

34. Simons PJ, van den Pangaart PS, van Roomen CP, Aerts JM, Boon L (2005) Cytokine-mediated modulation of leptin and adiponectin secretion during in vitro adipogenesis: evidence that tumor necrosis factor-alpha- and interleukin-1beta-treated human preadipocytes are potent leptin producers. Cytokine 32: 94-103

35. Kappes A, Loffler G (2000) Influences of ionomycin, dibutyrylcycloAMP and tumour necrosis factor-alpha on intracellular amount and secretion of apM1 in differentiating primary human preadipocytes. Horm Metab Res 32:548-554

36. Tilg H, Moschen AR (2006) Adipocytokines: mediators linking adipose tissue, inflammation and immunity. Nat Rev Immunol 6:772-783

37. Ptitsyn AA, Zvonic S, Conrad SA, Scott LK, Mynatt RL, Gimble JM (2006) Circadian clocks are resounding in peripheral tissues. PLoS Comput Biol 2:e16 
38. Zvonic S, Ptitsyn AA, Conrad SA et al (2006) Characterization of peripheral circadian clocks in adipose tissues. Diabetes 55:962970

39. Turek FW, Joshu C, Kohsaka A et al (2005) Obesity and metabolic syndrome in circadian Clock mutant mice. Science 308: 1043-1045
40. Rudic RD, McNamara P, Curtis AM et al (2004) BMAL1 and CLOCK, two essential components of the circadian clock, are involved in glucose homeostasis. PLoS Biol 2:e377

41. Russell CD, Petersen RN, Rao SP et al (1998) Leptin expression in adipose tissue from obese humans: depot-specific regulation by insulin and dexamethasone. Am J Physiol 275:E507-E515 